\title{
Improving understanding of microclimate heterogeneity within a contemporary plant growth facility to advance climate control and plant productivity
}

\author{
Evan Kutta ${ }^{1}$, Jason Hubbart ${ }^{2,}$ * \\ ${ }^{1}$ Department of Forestry, School of Natural Resources, University of Missouri, Columbia, USA \\ ${ }^{2}$ Department of Forestry, Water Resources Program, School of Natural Resources, University of Missouri, Columbia, USA \\ Email address: \\ ejk3md@gmail.com (E. Kutta), hubbartj@missouri.edu (J. Hubbart)
}

\section{To cite this article:}

Evan Kutta, Jason Hubbart. Improving Understanding of Microclimate Heterogeneity within a Contemporary Plant Growth Facility to Advance Climate Control and Plant Productivity. Journal of Plant Sciences. Vol. 2, No. 5, 2014, pp. 167-178.

doi: $10.11648 /$ j.jps.20140205.14

\begin{abstract}
Greenhouse crop production is maximized by maintaining optimal growing conditions. Accurate management of climate conditioning equipment based on measurements of the internal greenhouse microclimate is necessary to optimize crop production. Traditionally, greenhouse microclimate is monitored by a single suite of sensors located at a fixed (often central) location that is considered representative of the entire greenhouse climate. To advance greenhouse crop production additional sensors may better represent greenhouse microclimate heterogeneity and improve performance of climate conditioning equipment. However, elucidating the proper number and distribution of additional sensors requires investigation. Distributed high resolution air temperature $(n=63)$, relative humidity $(n=63)$, and incoming solar radiation data were collected between May $9^{\text {th }}, 2012$ and September $5^{\text {th }}, 2012$ to test the efficacy of conventional centrally located sensors to characterize the spatial and temporal climate variability inside three contemporary greenhouse facilities. Results indicate substantial microclimate heterogeneity with mean horizontal temperature gradients of as much as $5.0^{\circ} \mathrm{C} / \mathrm{m}$, and mean horizontal VPD gradients of 1.5 $\mathrm{kPa} / \mathrm{m}$. Most substantially, the maximum vertical temperature gradient was $11.65^{\circ} \mathrm{C} / \mathrm{m}$. Results indicate that as few as five properly deployed sensor assemblages (e.g. temperature, humidity, solar radiation) may be necessary to more accurately monitor horizontal and vertical microclimate heterogeneity in a typical greenhouse room. This would improve climate conditioning accuracy and improve the homogeneity of the internal greenhouse climate, which may result in increased productivity and profits for greenhouse managers.
\end{abstract}

Keywords: Horticulture, Plant Productivity, Greenhouse Climate Control, Microclimate Heterogeneity

\section{Introduction}

Controlled environment agriculture serves an important role in the global production of fresh produce [1]. This is because controlled environment production methods often create longer cropping periods and resource homogeneity (i.e. water, temperature, light, etc), and increased yield relative to field-grown produce. Many contemporary greenhouse facilities use adaptive climate control technologies to optimize environmental conditions for plant growth [2]. Greenhouse-grown produce are also theoretically protected from harsh environmental conditions, thereby potentially maintaining higher nutritional quality and aesthetic appeal and increased market value relative to field-grown products [1]. The combination of increased yield, quality, and a longer production season often justifies operational costs associated with greenhouse production [3]. However, unlike heating, for which technology is relatively well established, greenhouse cooling frequently presents considerable technological challenges [4]. For example, while too little sunlight can require artificial greenhouse lighting and heating, too much sunlight can result in too much heat for optimal greenhouse production, especially during hot external conditions [5]. Sethi et al. (2007) [4] showed that evaporative cooling is the most effective means of greenhouse cooling in regions where ambient temperatures approach $40^{\circ} \mathrm{C}$ annually. However, evaporative cooling can lead to heterogeneous distribution of temperature with horizontal gradients up to $0.13^{\circ} \mathrm{C} / \mathrm{m}[6]$ and vertical temperature gradients up to $6.7^{\circ} \mathrm{C} / \mathrm{m}[7]$.

Temperature and relative humidity are two of the most 
important climate variables in a greenhouse. Temperature directly affects the rate of chemical reactions in plants [1] and temperature and relative humidity directly affects the concentration gradient driving leaf water vapor diffusion [8]. Sethi et al. (2007) [4] showed that a pad-fan evaporative cooling system lowered greenhouse air temperature between $4-6^{\circ} \mathrm{C}$ and up to $12^{\circ} \mathrm{C}$ if used with shading. Van Pec and Berckmans (1999) [9] showed that greenhouse air temperature gradients variably influenced leaf temperature resulting in heterogeneous rates of photosynthesis and transpiration. Spatial variation of relative humidity within a greenhouse was noted in multiple previous studies but not assessed ([6]; [10]). Maintaining vapor pressure deficit (VPD) values between 0.2 and $1.0 \mathrm{kPa}$ was shown to have little effect on the growth and development of crops [11]. However, maximum transpiration rates for well-watered rose [12], maize [13], sorghum ([14]; [15]), and soybean [16] crops have been identified at VPD values between 1.6 and $2.7 \mathrm{kPa}$. VPD values above $\sim 2.0 \mathrm{kPa}$ was shown to limit production for a variety of crops due to the shared path between carbon and water exchange between the leaf and the atmosphere [13].

Despite the potential for uneven distribution of temperature and relative humidity throughout a greenhouse it is common practice to install a single sensor assemblage (i.e. temperature and humidity) at a fixed point assumed representative of an entire greenhouse room [2]. This is the popular approach since additional sensors require additional power and infrastructure, which increases the complexity and expense associated with the climate controller's software, equipment, and maintenance [2]. Given the aforementioned issues and meteorological complexities, studies using an array of distributed sensors to quantitatively characterize environmental heterogeneity in contemporary greenhouse environments could provide critically needed information to greenhouse managers wishing to improve current climate management practices to increase crop profitability.

The overall objective of the following study was to quantitatively characterize temporal and spatial variability of greenhouse temperature, relative humidity and incoming solar radiation during the summer of $2012(5 / 9$ - 9/5) in a contemporary plant growth facility. Sub-objectives included, a) compare a standard centralized climate monitoring sensor to the corresponding instantaneous average of an array of sensors distributed evenly throughout a greenhouse room, b) quantify spatial variability in vapor pressure deficit as a proxy for plant transpiration, and c) provide recommendations to greenhouse managers about how to improve climate sensing accuracy to improve contemporary greenhouse climate control systems.

\section{Materials and Methods}

\subsection{Greenhouse Facility}

The greenhouse facility used in the current work was located in Columbia, Missouri on the University of Missouri (MU) campus $\left(38^{\circ} 95^{\prime}\right.$ latitude and $92^{\circ} 32^{\prime}$ longitude at an altitude of $237 \mathrm{~m}$ above sea level). The Sears Plant Growth
Facility was built in 2001 consisting of 12 separate greenhouse rooms that are $6 \mathrm{~m}$ wide in the east-west direction and $22 \mathrm{~m}$ long in the north-south direction (area $=132 \mathrm{~m}^{2}$ ). Three of the rooms were utilized for the current investigation (Fig. 1). Rooms at either end of the multi-room greenhouse were not used for this study to avoid exterior edge effects that may have differentially altered microclimates of end-rooms relative to interior rooms. The single pane glass used for the roof and walls of each room did not prevent light transmission between rooms.

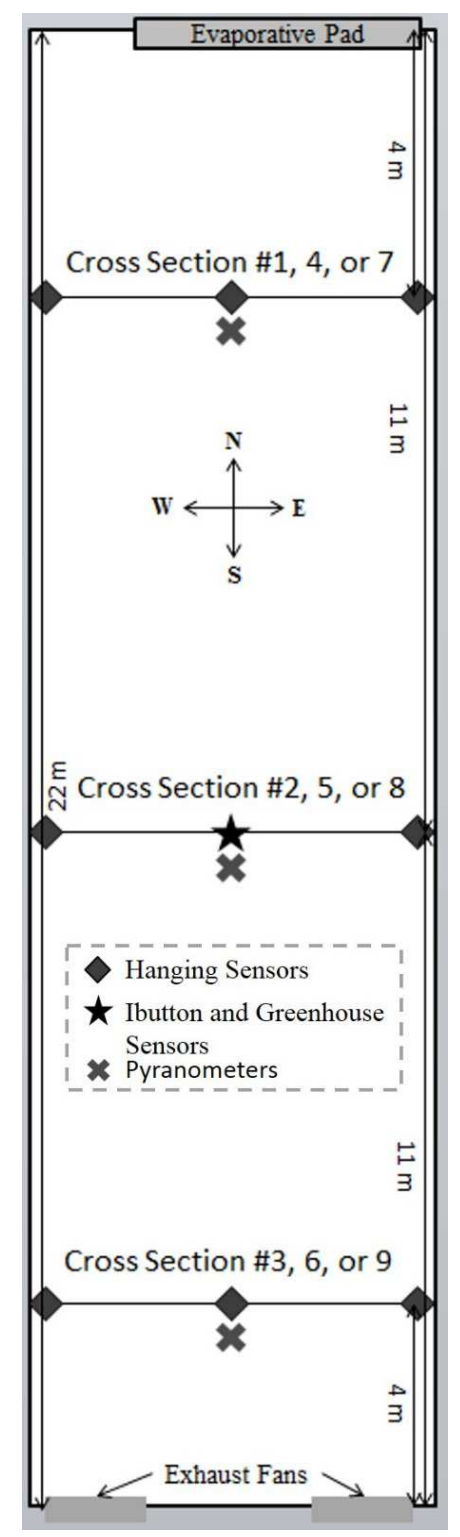

Figure 1. Representative top down view of the sensor array used in the current study in the Sears Plant Growth Facility located at the University of Missouri, Columbia, MO, USA. Cross section \# refers to the respective cross section array (room 102 is \#1-3, room 105 is \#4-6, and room 109 is \#7-9).

At the time of this work, each greenhouse room was controlled by an autonomous Growmaster Procom environmental computer control designed by Micro-Grow Greenhouse Systems Inc. The Growmaster Procom environmental control system managed ventilation, shading, heating, four-stage cooling, and the artificial 
lighting system of each room.

The active cooling system had four stages of cooling; where each stage was separated by $1.11^{\circ} \mathrm{C}$ with the final stage utilizing evaporative cooling. Each room's climate control system had different optimal day and night temperatures based on the crop being grown in that room (Table 1). Optimal conditions were maintained through the ON/OFF manipulation of climate conditioning equipment based on climate control action temperatures (Table 1). Rooms 102, 105, and 109 were chosen for this study to determine whether or not maize (109) or soybean (105) presence and morphology (i.e. plant height) influenced microclimate heterogeneity relative to an empty (102) greenhouse room. It was not the intent to directly quantify plant physiological response to altered greenhouse microclimate in the current work. The climate control was shut off in rooms 102, 109, and 105 for sterilization on $6 / 29 / 12,8 / 7 / 12$, and $8 / 29 / 12$ respectively to allow each greenhouse room to warm to temperatures hot enough to exterminate pests or pathogens.

Table 1. Climate Control objectives and action temperature for each greenhouse room studied at the Sears Plant Growth Facility located at the University of Missouri, Columbia, MO, USA. (*) indicates night time action temperature).

\begin{tabular}{lllllll}
\hline \multirow{2}{*}{ Room } & \multirow{2}{*}{ Crop } & Objective & \multicolumn{3}{c}{ Climate Control Action Temperature } \\
\cline { 3 - 7 } & & ODT & ONT & Heating & RV & AC \\
\hline $\mathbf{1 0 2}$ & Empty & 22.00 & 22.00 & 17.78 & 20.00 & 21.67 \\
$\mathbf{1 0 5}$ & Soybean & 29.00 & 24.00 & 23.89 & 26.67 & 29.44 \\
$\mathbf{1 0 9}$ & Corn & 25.00 & 20.00 & $21.67,20.00 *$ & $23.89,22.22 *$ & $26.11,24.44 *$ \\
\hline
\end{tabular}

ODT $=$ Optimal Daytime Temperature, ONT = Optimal Nighttime Temperature, RV = Ridge Vent, AC = Active Cooling, DSC = Draw Shade Curtain.

\subsection{Equipment and Instrumentation}

Standard greenhouse equipment included one centrally located aspirated temperature and relative humidity sensor hereafter referred to as internal system sensors. Incoming solar radiation data were collected using an externally mounted pyranometer recording data in lux, hereafter referred to as an external system sensor. For the current research, each room was equipped with 21 iButton hygrochrons (Dallas Maxim Inc.; [17]) with radiation shields [18] (total sample size $=63$ ) and three Apogee pyranometers (total sample size $=$ 9) (Decagon Devices Inc.). Pyranometers sensed incoming shortwave radiation at hourly intervals, on the hour. Apogee pyranometers have a $180^{\circ}$ field of view and an accuracy of $+/$ $5 \%$ between 0 and $1750 \mathrm{~W} / \mathrm{m}^{2}$. IButton temperature (Ta) relative humidity $(\mathrm{Rh})$ sensors were programmed to record data at hourly intervals, on the hour. IButton sensors have temperature accuracy of $+/-0.5^{\circ} \mathrm{C}$ and are inexpensive and durable sensors that are well suited for obtaining accurate spatially distributed climate data ([17]. Hygrochron iButton sensors were used to observe the distribution of temperature and relative humidity and were deployed in a manner to obtain three cross section arrays throughout each room at distances of 4, 11, and 18 meters from the evaporative pads (Fig. 1).

Each cross section array consisted of three sensor hangers with one hanger approximately $25 \mathrm{~cm}$ from each wall and the third hanging in the center of the room. Hangers near either wall had hygrochron iButtons placed at 1 and $3 \mathrm{~m}$ above the floor, while the central hanger was equipped with iButtons installed 1,2, and $3 \mathrm{~m}$ above the floor. Internal pyranometers were attached to each of the central hangers at $1 \mathrm{~m}$ above the floor or approximately bench height. Hygrochron iButton and pyranometer sensors recorded hourly data between $5 / 9 / 12$ and 9/5/12. The Growmaster Procom controller relies solely on one centrally located, bench-height fan-aspirated temperature and relative humidity sensor to monitor environmental conditions and trigger heating or cooling when set points were reached (Table 1). External climate variables including temperature, relative humidity, incoming solar radiation, and wind speed and direction were recorded on the roof of the greenhouse and at Sanborn Field, a climate monitoring station maintained by University of Missouri Extension located 0.36 km southeast of the Sears Plant Growth Facility.

The external climate during the study was analyzed to assess the impacts of external conditions on climate control accuracy and internal greenhouse climate. The average internal climate for each room was compared to the average ambient external climate. Room averages were compared to assess whether different climate control action temperatures and crops influenced microclimate heterogeneity. Horizontal distribution of temperature and relative humidity were estimated to characterize the magnitude of horizontal climate heterogeneity. Finally, the vertical distribution of temperature and relative humidity were estimated to assess the magnitude of vertical climate heterogeneity.

Ambient temperature $(\mathrm{Ta})$, relative humidity $(\mathrm{Rh})$, and shortwave radiation data were statistically compared within and between rooms using one-way repeated measures analysis of variance (ANOVA) at hourly, daily, weekly, and monthly time steps $(p \leq 0.05)$ ([7], [19], [20], [21], [22]). One-way ANOVA was followed with Tukey's post hoc multiple-comparison test (where appropriate) to compare the different locations in each room and temperature, relative humidity, and incoming solar radiation in all possible combinations [22]. Vapor pressure deficit (VPD) was calculated as a proxy to assess potential transpiration demand of crops at various locations in each room. The empirical Teten's formula [23] was used to calculate saturation vapor pressure $\left(\mathrm{e}_{\mathrm{s}}\right)$ in $\mathrm{kPa}$ where $\mathrm{T}$ is the observed ambient temperature in degrees Celsius $\left({ }^{\circ} \mathrm{C}\right)$ :

$$
e_{s}(T)=0.611 e^{\frac{(17.502 \times T)}{(T+240.97)}}
$$

To estimate actual vapor pressure $\left(\mathrm{e}_{\mathrm{a}}\right)$ the saturation vapor pressure must be multiplied by relative humidity $\left(h_{r}\right)$. 


$$
\mathrm{e}_{\mathrm{a}}=\mathrm{h}_{\mathrm{r}} \times \mathrm{e}_{\mathrm{s}}\left(\mathrm{T}_{\mathrm{a}}\right)
$$

To estimate the VPD $(\mathrm{kPa})$ the actual vapor pressure is subtracted from the saturation vapor pressure [24].

$$
\mathrm{VPD}=\mathrm{e}_{\mathrm{s}}\left(\mathrm{T}_{\mathrm{a}}\right)-\mathrm{e}_{\mathrm{a}}
$$

The ambient lapse rate was calculated by the change (d) of temperature (dT) with respect to change in height (dz). Where $\mathrm{dT}$ is the upper temperature $\left(\mathrm{T}_{\mathrm{u}}\right)$ minus the lower temperature $\left(T_{1}\right)$ and $d z$ is the upper height $\left(z_{u}\right)$ minus the lower height $\left(\mathrm{z}_{1}\right)$.

$$
L R=\frac{d T}{d z}=\frac{T_{u}-T_{1}}{z_{u}-z_{1}}
$$

Erroneous or missing data were replaced with mathematically modeled values. Data gaps less than three hours in length were filled by interpolation (i.e. 3-point spline) [25]. Large data gaps exceeding three hours in length were caused by sensor failure and were filled by calculating values based on linear regression models created from data from one of the nearby sensors located in the same room at the same height for the ten days preceding and the ten days following the data gap $\left(\mathrm{R}^{2}\right.$ values $\left.<0.97\right)$.

\section{Results}

\subsection{Climate during Study}

Climate during the study $(5 / 9 / 12$ to $9 / 5 / 12)$ was characterized by extreme (D3) to exceptional (D4) drought (USDM Drought Severity Classification; [26] accompanied by above average temperatures. Using the local Columbia Regional Airport's 123 year climate record the June-August period in 2012 ranked as the $9^{\text {th }}$ driest on record with only 5.84 " of precipitation. This period was the $6^{\text {th }}$ hottest on record with average temperature of $26.83^{\circ} \mathrm{C}$. During this period a high temperature of at least $32.2^{\circ} \mathrm{C}$ was reported for 66 of the 92 days. This was the $3^{\text {rd }}$ greatest number of occurrences of such high temperatures in the time-period on record. There is therefore great value in the current work in that climate conditions provided a worst case scenario for drought conditions and greenhouse management.

\subsection{External versus Internal Climate}

At the Sanborn Field climate station the average temperature, relative humidity, and incoming solar radiation was $25.9^{\circ} \mathrm{C}, 53.5 \%$, and $259.3 \mathrm{~W} / \mathrm{m}^{2}$ respectively from $5 / 9 / 12$ to $9 / 5 / 12$ (Table 2). Averaging data collected by the centrally located greenhouse sensors located at bench height in all 3 rooms (Fig. 1) yielded a study average temperature and relative humidity of $28.8^{\circ} \mathrm{C}$ and $51.3 \%$ respectively.

Averaging all data collected by iButton sensors that were evenly distributed throughout each greenhouse room (Fig. 1, n $=21 /$ room) yielded a study average temperature and relative humidity of $32.5^{\circ} \mathrm{C}$ and $45.7 \%$ respectively. Standard deviation of study averaged temperature data was $6.25^{\circ} \mathrm{C}$, $4.58^{\circ} \mathrm{C}$, and $5.96^{\circ} \mathrm{C}$ for iButton sensors, centrally located greenhouse, and Sanborn Field data, respectively. Therefore the spatially distributed iButton sensors detected greater internal temperature variability relative to external conditions over the period of study, which was not detected by the centrally located greenhouse sensors. Standard deviation of study averaged relative humidity data were $14.84 \%, 13.06 \%$, and $19.01 \%$ for spatially distributed iButton, centrally located greenhouse, and Sanborn Field data respectively. Internal relative humidity was less variable than external conditions, but averages of both spatially distributed iButton and centrally located greenhouse sensors indicated lower internal RH values than external conditions. Therefore, plants in greenhouse rooms were consistently exposed to warmer and drier conditions than plants located at Sanborn Field. Comparing incoming solar radiation data between the externally mounted greenhouse sensor and either Sanborn Field or internal study pyranometers was not possible due to incompatible units of measurement (English lux to metric $\mathrm{W} / \mathrm{m}^{2}$ ). Average incoming solar radiation values were 82.5 $\mathrm{W} / \mathrm{m}^{2}, 30.5 \mathrm{lux}$, and $259.3 \mathrm{~W} / \mathrm{m}^{2}$ for spatially distributed internal pyranometers, the externally-mounted greenhouse sensor, and the nearby Sanborn Field sensor respectively. Standard deviation was $97.5 \mathrm{~W} / \mathrm{m}^{2}, 36.6 \mathrm{lux}$, and $320.2 \mathrm{~W} / \mathrm{m}^{2}$ for spatially distributed pyranometers, externally mounted greenhouse, and Sanborn Field sensors respectively. Statistical analyses of spatially distributed iButton, centrally located greenhouse, and Sanborn Field data sets indicated significant differences $(\mathrm{P}<0.001, \mathrm{CI}=0.05)$ between spatially distributed iButtons, centrally located greenhouse, and external Sanborn Field sensors for temperature, relative humidity, and incoming solar radiation data.

Table 2. Descriptive statistics of air temperature $\left({ }^{\circ} \mathrm{C}\right)$, relative humidity $(\%)$, and incoming solar radiation (lux or $\mathrm{W} / \mathrm{m}^{2}$ ) data comparing centrally located greenhouse, iButton, and Sanborn Field sensors deployed at the Sears Plant Growth Facility located at the University of Missouri, Columbia, MO, USA.

\begin{tabular}{lllll}
\hline Variable & Statistic & iButton & Greenhouse & Sanborn Field \\
\hline & Mean & 32.53 & 28.77 & 25.94 \\
Ta $\left({ }^{\circ} \mathbf{C}\right)$ & Min & 21.81 & 20.49 & 9.00 \\
& Max & 51.91 & 47.41 & 39.50 \\
& Std Dev & 6.25 & 4.58 & 5.96 \\
& Mean & 45.67 & 51.30 & 53.52 \\
RH (\%) & Min & 9.72 & 13.56 & 16.00 \\
& Max & 86.63 & 87.56 & 96.00 \\
& Std Dev & 14.84 & 13.06 & 19.01 \\
& Solar Radiation & & \\
& Mean & 82.54 & $30.45^{*}$ & 259.33 \\
Lux (*) or & Min & 0.00 & $0.00^{*}$ & 0.00 \\
W/m & Max & 510.25 & $119.64^{*}$ & 1001.00 \\
& Std Dev & 97.57 & $36.63^{*}$ & 320.21 \\
\hline
\end{tabular}

$\mathrm{Ta}=$ ambient temperature $\left({ }^{\circ} \mathrm{C}\right), \mathrm{RH}=$ relative humidity $(\%), \mathrm{ISR}=$ incoming solar radiation (lux $[*]$ or $\mathrm{W} / \mathrm{m}^{2}$ )

\subsection{Climate Comparison between Rooms}

Each greenhouse room had different climate control objectives between 5/9/12 and 9/5/12 (Table 1) and different climate control shut-off dates. The average of desired day and 
night temperature objectives were $22.0,26.5$, and $22.5^{\circ} \mathrm{C}$ for rooms 102, 105, and 109 respectively. Room average temperatures (Table 3) recorded by centrally located greenhouse sensors between 5/9/12 and 9/5/12 were 29.6, 28.6, and $28.1^{\circ} \mathrm{C}$ for rooms 102,105 , and 109 respectively. Room average temperatures recorded by spatially distributed iButton sensors between $5 / 9 / 12$ and $9 / 5 / 12$ were $32.0,33.0$, and $32.4^{\circ} \mathrm{C}$ for rooms 102, 105, and 109 respectively. The permanent centrally located greenhouse sensors provided study average relative humidity values of 50.8, 47.9 , and $55.1 \%$ for rooms 102 , 105 , and 109 respectively. Spatially distributed iButton sensors provided study average relative humidity values of 45.8, 44.0, and $47.2 \%$ for rooms 102,105 , and 109 respectively.
Statistically significant differences $(\mathrm{P}$ values $<0.028)$ were calculated between centrally located greenhouse and spatially distributed temperature data sets except between iButton data collected in rooms 102 and room 109 ( $\mathrm{P}$ value $=0.938)$. Statistically significant differences $(\mathrm{P}<0.001)$ were detected between all centrally located greenhouse and spatially distributed iButton sensor relative humidity data sets except between centrally located greenhouse and centrally located iButton relative humidity data collected in room $102(\mathrm{P}=0.268)$ and room $105(\mathrm{P}=0.115)$. However, relative humidity data sets were significantly different $(\mathrm{P}<0.05)$ between greenhouse rooms (i.e. room 102 compared to room 109).

Table 3. Descriptive statistics of air temperature $\left({ }^{\circ} \mathrm{C}\right)$, relative humidity $(\%)$, and incoming solar radiation $\left(\mathrm{W} / \mathrm{m}^{2}\right)$ data collected by centrally located $($ left $)$ and spatially distributed sensors (right) deployed at the Sears Plant Growth Facility located at the University of Missouri, Columbia, MO, USA.

\begin{tabular}{|c|c|c|c|c|c|c|c|}
\hline \multirow{2}{*}{ Variable } & \multirow{2}{*}{ Statistic } & \multicolumn{3}{|c|}{ Centrally Located Greenhouse Sensors } & \multicolumn{3}{|c|}{ Spatially Disributed iButton Sensors } \\
\hline & & Room 102 & Room 105 & Room 109 & Room 102 & Room 105 & Room 109 \\
\hline \multirow{4}{*}{ Ta $\left({ }^{\circ} \mathbf{C}\right)$} & Mean & 29.57 & 28.56 & 28.07 & 32.00 & 32.96 & 32.35 \\
\hline & Min & 18.33 & 21.94 & 20.65 & 18.84 & 22.15 & 20.74 \\
\hline & Max & 48.89 & 46.11 & 48.89 & 56.97 & 48.46 & 58.07 \\
\hline & Std Dev & 7.79 & 2.85 & 4.42 & 8.18 & 4.96 & 6.65 \\
\hline \multirow{5}{*}{ RH (\%) } & Mean & 50.79 & 47.87 & 55.05 & 45.83 & 44.02 & 47.16 \\
\hline & Min & 12.00 & 14.00 & 12.00 & 5.73 & 12.75 & 6.55 \\
\hline & Max & 95.83 & 85.00 & 91.67 & 90.71 & 86.50 & 90.66 \\
\hline & Std Dev & 19.25 & 11.12 & 15.42 & 19.08 & 13.51 & 16.39 \\
\hline & & \multicolumn{3}{|c|}{ Centrally Located Pyranometer } & \multicolumn{3}{|c|}{ Spatially Distributed Pyranometers } \\
\hline \multirow{4}{*}{$\begin{array}{l}\text { ISR (lux }[*] \text { or } \\
\left.\text { W/m } \mathbf{m}^{2}\right)\end{array}$} & Mean & $30.35^{*}$ & $30.38^{*}$ & $30.30 *$ & 52.86 & 71.51 & 122.73 \\
\hline & Min & $0.00 *$ & $0.00 *$ & $0.00 *$ & 0.00 & 0.00 & 0.00 \\
\hline & Max & $120.00^{*}$ & $119.67 *$ & $119.60 *$ & 220.95 & 690.92 & 711.06 \\
\hline & Std Dev & $36.56^{*}$ & $36.59 *$ & $36.51^{*}$ & 64.62 & 90.43 & 149.61 \\
\hline
\end{tabular}

$\mathrm{Ta}=$ ambient temperature, $\mathrm{RH}=$ relative humidity, ISR $=$ incoming solar radiation $\left(\mathrm{lux}[*]\right.$ or $\left.\mathrm{W} / \mathrm{m}^{2}\right)$

\subsection{Climate within Rooms}

Average temperatures recorded by centrally located greenhouse sensors were $23.5,28.4$ and $27.1^{\circ} \mathrm{C}$ for rooms 102 , 105, and 109 respectively (Table 4). Average temperatures recorded by spatially distributed iButton sensors were 23.4, 31.6 , and $29.1^{\circ} \mathrm{C}$ for rooms 102,105 , and 109 respectively. The greatest difference between average temperatures and desired optimal temperatures while the climate control system was $\mathrm{ON}$ was in room 105 , where on average, the centrally located greenhouse sensor was $1.9^{\circ} \mathrm{C}(7.1 \%)$ warmer and the centrally located iButton sensor was $5.1^{\circ} \mathrm{C}(19.2 \%)$ warmer than the desired optimal temperature of $26.5^{\circ} \mathrm{C}$ (Table 1). Average VPD values were estimated to be 2.0 and $2.6 \mathrm{kPa}$ at centrally located greenhouse and iButton sensors. Those values were at or above the $2.0 \mathrm{kPa}$ threshold for stomatal closure identified for soybeans by [16].

Table 4. Descriptive statistics of temperature $\left({ }^{\circ} \mathrm{C}\right)$, relative humidity $(\%)$, and calculated vapor pressure deficit (kPa) using centrally located iButton temperature and relative humidity and greenhouse sensors while the climate control system was ON at the Sears Plant Growth Facility located at the University of Missouri, Columbia, MO, USA.

\begin{tabular}{|c|c|c|c|c|c|c|c|}
\hline & \multirow{2}{*}{ Statistic } & \multicolumn{3}{|c|}{ Central Greenhouse Sensors } & \multicolumn{2}{|c|}{ Central iButton Sensors } & \multirow[b]{2}{*}{$\# \mathbf{8 a}$} \\
\hline & & 102 & 105 & 109 & $\# \mathbf{2 a}$ & $\# \mathbf{5 a}$ & \\
\hline \multirow{4}{*}{ Ta $\left({ }^{\circ} \mathrm{C}\right)$} & Mean & 23.51 & 28.40 & 27.14 & 23.41 & 31.62 & 29.08 \\
\hline & Min & 18.33 & 21.94 & 20.65 & 19.04 & 22.15 & 20.85 \\
\hline & Max & 31.11 & 40.65 & 33.98 & 40.39 & 45.53 & 40.45 \\
\hline & Std Dev & 2.68 & 2.43 & 2.71 & 2.38 & 3.69 & 3.90 \\
\hline \multirow{4}{*}{ RH (\%) } & Mean & 64.14 & 47.60 & 58.48 & 66.95 & 46.44 & 56.56 \\
\hline & Min & 33.33 & 20.67 & 25.83 & 19.15 & 15.82 & 18.22 \\
\hline & $\operatorname{Max}$ & 95.83 & 82.00 & 86.00 & 92.32 & 83.76 & 86.82 \\
\hline & Std Dev & 12.37 & 10.27 & 11.52 & 13.15 & 11.64 & 12.88 \\
\hline \multirow{4}{*}{ VPD (kPa) } & Mean & 1.03 & 2.04 & 1.32 & 0.95 & 2.61 & 1.59 \\
\hline & Min & 0.11 & 0.57 & 0.46 & 0.23 & 0.56 & 0.45 \\
\hline & Max & 1.87 & 6.00 & 2.71 & 6.04 & 8.05 & 5.27 \\
\hline & Std Dev & 0.37 & 0.58 & 0.57 & 0.45 & 1.02 & 0.88 \\
\hline
\end{tabular}

$\mathrm{Ta}=$ Ambient Temperature, $\mathrm{RH}=$ Relative Humidity, VPD $=$ Vapor Pressure Deficit 
Absolute maximum VPD values were 6.0 and $8.1 \mathrm{kPa}$ for centrally located greenhouse and iButton sensors respectively, which were $4.0(200 \%)$ or $6.1 \mathrm{kPa}(305 \%)$ greater than the 2.0 $\mathrm{kPa}$ threshold identified by [16]. Statistically significant differences $(\mathrm{P}<0.001, \mathrm{CI}=0.05)$ were shown between temperature data collected by each set of centrally located iButton and greenhouse sensors. Statistically significant differences $(\mathrm{P}<0.001, \mathrm{CI}=0.05)$ were detected between relative humidity data collected by each set of centrally located iButton (naturally-aspirated) and greenhouse sensors (fan-aspirated). Therefore, despite being located less than $1 \mathrm{~m}$ apart the difference in aspiration can still be significant. This observation is consistent with the results of [18]. Statistically significant differences $(\mathrm{P}<0.001, \mathrm{CI}=0.05)$ were shown between VPD calculations made from data collected by the centrally located iButton and greenhouse sensors except in room $102(\mathrm{P}=0.093)$.
Table 5 presents descriptive statistics for cross section averages of temperature, relative humidity, and incoming solar radiation data collected by spatially distributed iButton sensors and pyranometers while the climate control system was $\mathrm{ON}$ in each room. Each room contained three cross sections $(102=\operatorname{CS} 1$ to $3,105=\operatorname{CS} 4$ to 6 , and $109=\operatorname{CS} 7$ to 9 ; Fig. 1). Cross section averages in room 102 of temperature data were $27.05,27.46$, and $27.6^{\circ} \mathrm{C}$ with average relative humidity values of 58.06, 54.97, and $54.67 \%$ for cross sections 1, 2, and 3 respectively. The cross section averages in room 105 of temperature data were $31.63,33.67$, and $33.65^{\circ} \mathrm{C}$ with average relative humidity values of $46.8,42.01$, and $41.35 \%$ for cross sections 4,5 , and 6 respectively. Cross section averages in room 109 of temperature data were 31.06, 32.94 , and $32.58^{\circ} \mathrm{C}$ with average relative humidity values of $51.83,47.4$, and $47.28 \%$ for cross sections 7,8 , and 9 respectively (Table 1).

Table 5. Descriptive statistics of air temperature $\left({ }^{\circ} \mathrm{C}\right)$, relative humidity $(\%)$, and incoming solar radiation $\left(\mathrm{W} / \mathrm{m}^{2}\right)$ collected by iButton and pyranometer sensors while the climate control was ON located at the Sears Plant Growth Facility located at the University of Missouri, Columbia, MO, USA.

\begin{tabular}{|c|c|c|c|c|c|c|c|c|c|c|}
\hline & \multirow{2}{*}{ Statistic } & \multicolumn{3}{|c|}{ Room 102} & \multicolumn{3}{|c|}{ Room 105} & \multicolumn{3}{|c|}{ Room 109} \\
\hline & & CS \#1 & $\mathrm{CS} \# 2$ & $\mathrm{CS} \# \mathbf{3}$ & CS \#4 & CS \#5 & CS \#6 & CS \#7 & $\mathrm{CS} \# \mathbf{8}$ & CS \#9 \\
\hline \multirow{4}{*}{ Ta $\left({ }^{\circ} \mathrm{C}\right)$} & Mean & 27.05 & 27.46 & 27.60 & 31.63 & 33.67 & 33.65 & 31.06 & 32.94 & 32.58 \\
\hline & Min & 18.82 & 18.86 & 18.70 & 22.17 & 22.08 & 22.13 & 20.65 & 20.94 & 20.64 \\
\hline & Max & 44.50 & 44.31 & 44.11 & 42.09 & 46.66 & 50.18 & 43.86 & 47.68 & 47.20 \\
\hline & Std Dev & 5.23 & 5.55 & 5.68 & 3.71 & 5.51 & 5.50 & 5.68 & 6.70 & 6.26 \\
\hline \multirow{3}{*}{ RH (\%) } & Mean & 58.06 & 54.97 & 54.67 & 46.80 & 42.01 & 41.35 & 51.83 & 47.40 & 47.28 \\
\hline & Min & 17.32 & 16.69 & 17.37 & 15.66 & 11.61 & 9.67 & 19.75 & 15.47 & 15.44 \\
\hline & Std Dev & 13.25 & 14.46 & 14.72 & 11.87 & 13.36 & 13.40 & 13.06 & 14.63 & 14.13 \\
\hline \multirow{4}{*}{$\operatorname{ISR}\left(\mathbf{W} / \mathbf{m}^{2}\right)$} & Mean & 59.81 & 64.40 & 59.18 & 55.89 & 68.04 & 96.37 & 158.19 & 120.10 & 124.88 \\
\hline & Min & 0.00 & 0.00 & 0.00 & 0.00 & 0.00 & 0.00 & 0.00 & 0.00 & 0.00 \\
\hline & $\operatorname{Max}$ & 221.56 & 261.84 & 223.39 & 825.81 & 520.02 & 952.15 & 758.06 & 532.84 & 884.40 \\
\hline & Std Dev & 64.81 & 73.24 & 62.78 & 85.86 & 89.43 & 122.39 & 183.05 & 134.85 & 152.88 \\
\hline
\end{tabular}

$\mathrm{Ta}=$ Ambient Temperature, $\mathrm{RH}=$ Relative Humidity, ISR $=$ Incoming Solar Radiation, $\mathrm{CS}=$ Cross Section

The cross section averages of incoming solar radiation data were $(59.81,64.40,59.18),(55.89,68.04,96.37),(158.19$, 120.10 , and 124.88$) \mathrm{W} / \mathrm{m}^{2}$ for rooms 102,105 , and 109 respectively. Statistically significant differences $(\mathrm{P}<0.011, \mathrm{CI}$ $=0.05$ ) were shown between all cross section average temperature data collected by cross sections 4 through 9 except between central and south cross sections in rooms 105 (CS \#5 and 6, $\mathrm{P}=1.000$ ) and $109(\mathrm{CS} \# 8$ and 9, $\mathrm{P}=0.454)$. Statistically significant differences $(\mathrm{P}<0.001, \mathrm{CI}=0.05)$ were shown between all cross section average relative humidity data except data collected by CS 2 and $3(\mathrm{P}=1.000)$, CS 5 and $6(\mathrm{P}=0.698), \mathrm{CS} 8$ and $9(\mathrm{P}=1.00), \mathrm{CS} 4$ and $8(\mathrm{P}=0.837)$, and CS 4 and $9(\mathrm{P}=0.952)$. Statistically significant differences $(\mathrm{P}<0.001, \mathrm{CI}=0.05)$ were identified for all incoming solar radiation data collected by pyranometers 6 through 9 except between CS 8 and $9(\mathrm{P}=0.929)$. The only other statistically significant difference $(\mathrm{P}=0.006, \mathrm{CI}=0.05)$ was between cross sections 4 and 5 . The hourly averages of $1 \mathrm{~m}$ temperature data were $24.38,31.05$, and $28.12^{\circ} \mathrm{C}$ for rooms 102,105 , and 109 respectively.

Table 6 shows descriptive statistics for temperature data collected at $1 \mathrm{~m}$ and $3 \mathrm{~m}$ by spatially distributed iButton sensors and subsequent VPD calculations at $1 \mathrm{~m}$ and $3 \mathrm{~m}$ while the climate control system was $\mathrm{ON}$ in each room. Spatially distributed iButtons located at $1 \mathrm{~m}$ recorded temperatures $10.8,17.2$, and $25.0 \%$ warmer than the average of optimal day and night temperatures in rooms 102, 105, and 109 respectively. The hourly average $3 \mathrm{~m}$ temperature data were $30.9,35.3$, and $36.4^{\circ} \mathrm{C}$ for rooms 102,105 , and 109 respectively. The hourly average lapse rate calculations were $3.20,2.14$, and $4.15^{\circ} \mathrm{C} / \mathrm{m}$ for rooms 102,105 , and 109 respectively. Hourly averages of $1 \mathrm{~m}$ VPD data were 1.08 , 2.45 , and $1.56 \mathrm{kPa}$ for rooms 102,105 , and 109 respectively. Hourly averages of $3 \mathrm{~m}$ VPD data were $3.18,4.14,4.85 \mathrm{kPa}$ for rooms 102, 105, and 109 respectively, and hourly average lapse rate calculations were $1.05,0.85$, and $1.64 \mathrm{kPa} / \mathrm{m}$. Therefore, on average, taller soybean and maize plants were subjected to VPD values of $3.30 \mathrm{kPa}$ and $3.20 \mathrm{kPa}$ in rooms 105 and 109 respectively. Statistically significant differences $(\mathrm{P}<0.001, \mathrm{CI}=0.05)$ were shown between all room averaged $1 \mathrm{~m}$ and $3 \mathrm{~m}$ temperature data collected by spatially distributed iButtons except $3 \mathrm{~m}$ temperature data collected in rooms 105 and $109(\mathrm{P}=0.124)$. Statistically significant differences $(\mathrm{P}<0.001, \mathrm{CI}=0.05)$ were calculated between all room averaged $1 \mathrm{~m}$ and $3 \mathrm{~m}$ VPD calculations using iButton sensor data. 
Table 6. Descriptive statistics of air temperature $\left({ }^{\circ} \mathrm{C}\right)$ at bench height $(1 \mathrm{~m})$ and $3 \mathrm{~m}$, and lapse rate calculations $\left({ }^{\circ} \mathrm{C} / \mathrm{m}\right.$ or $\left.\mathrm{kPa} / \mathrm{m}\right)$ using iButton sensors while the climate control system was ON at the Sears Plant Growth Facility located at the University of Missouri, Columbia, MO, USA.

\begin{tabular}{|c|c|c|c|c|c|c|c|c|c|c|}
\hline & \multirow{2}{*}{ Statistic } & \multicolumn{3}{|c|}{ Room 102} & \multicolumn{3}{|c|}{ Room 105} & \multicolumn{3}{|c|}{ Room 109} \\
\hline & & $1 \mathrm{~m}$ & $3 m$ & LR & $1 \mathrm{~m}$ & $3 m$ & LR & $1 \mathrm{~m}$ & $3 m$ & LR \\
\hline \multirow{3}{*}{ Ta $\left({ }^{\circ} \mathrm{C}\right)$} & Mean & 24.38 & 30.78 & 3.20 & 31.05 & 35.33 & 2.14 & 28.12 & 36.42 & 4.15 \\
\hline & Min & 19.04 & 18.64 & -1.22 & 22.03 & 22.18 & -1.26 & 20.95 & 20.55 & -0.52 \\
\hline & Std Dev & 2.65 & 9.18 & 3.59 & 2.95 & 7.54 & 2.62 & 3.05 & 9.73 & 3.54 \\
\hline \multirow{3}{*}{$\begin{array}{l}\text { VPD } \\
(\mathbf{k P a})\end{array}$} & Mean & 1.08 & 3.18 & 1.05 & 2.45 & 4.14 & 0.85 & 1.56 & 4.85 & 1.64 \\
\hline & Min & 0.23 & 0.29 & -0.21 & 0.58 & 0.52 & -0.30 & 0.39 & 0.52 & -0.11 \\
\hline & Std Dev & 0.37 & 2.85 & 1.34 & 0.84 & 2.65 & 1.08 & 0.55 & 3.65 & 1.63 \\
\hline
\end{tabular}

$\mathrm{Ta}=$ Ambient Temperature, VPD $=$ Vapor Pressure Deficit, LR $=$ Lapse Rate

\section{Discussion}

\subsection{Internal Versus External Climate}

Fig. 2 shows hourly climate time series collected by spatially distributed iButton, centrally located greenhouse, and external Sanborn Field sensors between 5/9/2012 and $9 / 5 / 2012$ (Table 2). The climate control system was shut off on June $29^{\text {th }}$, August $29^{\text {th }}$, and August $7^{\text {th }}$ for rooms 102, 105, and 109 respectively. On average, spatially distributed iButton sensor and centrally located greenhouse sensors recorded temperatures $6.59^{\circ} \mathrm{C}(25.4 \%)$ and $2.93^{\circ} \mathrm{C}(10.9 \%)$ warmer than external conditions respectively. Spatially distributed iButton sensors and centrally located greenhouse sensors recorded average relative humidity values $7.85(14.7 \%)$ and $2.22 \%(4.1 \%)$ lower than external conditions recorded at Sanborn Field respectively. Average incoming solar radiation values were 82.54 and $259.33 \mathrm{~W} / \mathrm{m}^{2}$ for internal and external pyranometers respectively (Table 2 ).

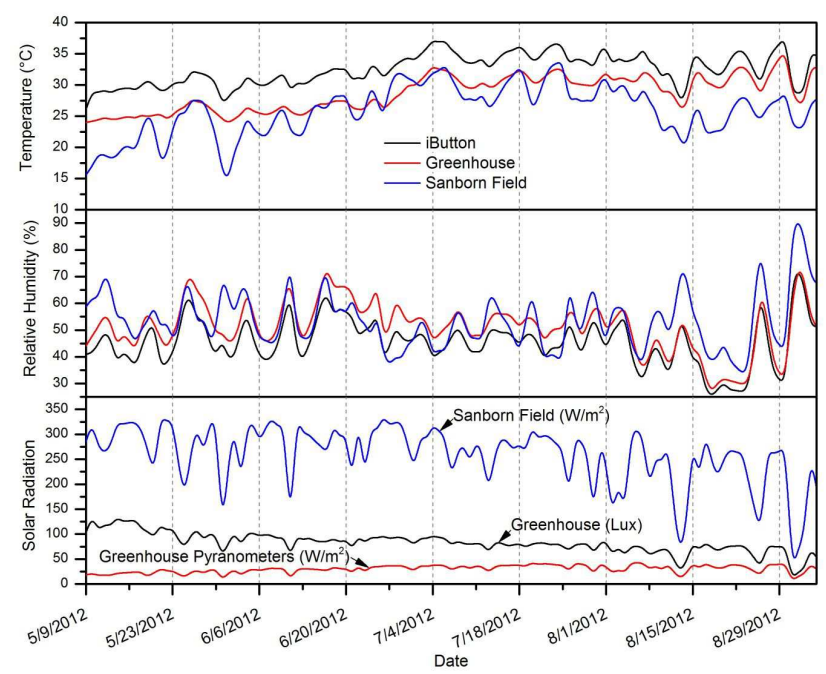

Figure 2. Daily time series of average air temperature $\left({ }^{\circ} \mathrm{C}\right)$, relative humidity (\%), and incoming solar radiation $\left(\mathrm{W} / \mathrm{m}^{2}\right)$ data collected between 5/9/12 and 9/5/12 at the Sears Plant Growth Facility and Sanborn Field located at the University of Missouri, Columbia, MO, USA. Greenhouse = Central greenhouse sensor.

The large difference in incoming solar radiation values between internal and external (Sanborn) pyranometers was presumably due to the transmittance of solar radiation through the greenhouse roof glazing material in addition to shadows caused by the greenhouse framing, shade curtains, and nearby plants or buildings. Statistical analysis of temperature, relative humidity, and incoming solar radiation data indicated significant differences $(\mathrm{P}<0.001, \mathrm{CI}=0.05)$ between each distributed iButton sensor or pyranometer, centrally located or externally mounted greenhouse sensors, and Sanborn Field data. Therefore, internal and external climate conditions were significantly different and each room's inter- and intra-average temperature, relative humidity, and incoming solar radiation were significantly different.

\subsection{Climate Comparison between Greenhouse Rooms}

Figure 3 shows daily averages of the hourly climate data time series collected by spatially distributed iButtons between $5 / 9 / 12$ and $9 / 5 / 12$. There was a substantial increase in variability for both temperature and relative humidity data when the climate control system was shut off (e.g. the $29^{\text {th }}$ of June, $28^{\text {th }}$ of August, and the $7^{\text {th }}$ of August for rooms 102, 105, and 109 respectively). The room average air temperatures recorded by distributed iButtons were $32.0,33.0$, and $32.3^{\circ} \mathrm{C}$ (Table 3) for rooms 102, 105, and 109, respectively. Baudoin et al. (1990) [27] considered maximum temperatures greater than $32^{\circ} \mathrm{C}$ to be excessive for greenhouse crops. The average temperature of each room in the current study was at or above $32^{\circ} \mathrm{C}$. The average of distributed iButtons from each room indicated temperatures of $10^{\circ} \mathrm{C}(45.5 \%), 6.5^{\circ} \mathrm{C}(24.5 \%)$, and $9.8^{\circ} \mathrm{C}(43.6 \%)$ warmer than average optimal day and night conditions (Table 1) for rooms 102, 105, and 109, respectively. The maximum difference between absolute minimum temperatures recorded by spatially distributed iButtons and the centrally located greenhouse sensor was only $0.51^{\circ} \mathrm{C}$ $(2.7 \%)$ recorded in room 102 . However, the absolute maximum temperatures recorded by spatially distributed iButtons were $8.08^{\circ} \mathrm{C}(16.5 \%), 2.35^{\circ} \mathrm{C}(5.1 \%)$, and $9.18^{\circ} \mathrm{C}$ $(18.8 \%)$ warmer than centrally located greenhouse sensors for rooms 102, 105, and 109 respectively. The differences between absolute minimum and maximum temperatures indicate that microclimate heterogeneity decreased at night and increased during the day. A greater magnitude of microclimate heterogeneity during the day when plants are photosynthesizing may promote variable crop growth rates 
within each greenhouse. As expected the opposite trend was apparent in absolute minimum and maximum relative humidity data. The centrally located greenhouse sensors recorded average relative humidity values $4.96,3.85$, and $7.89 \%$ higher than spatially distributed sensors in rooms 102 , 105 , and 109 respectively, thereby reporting cooler and moister conditions than those recorded by spatially distributed sensors.

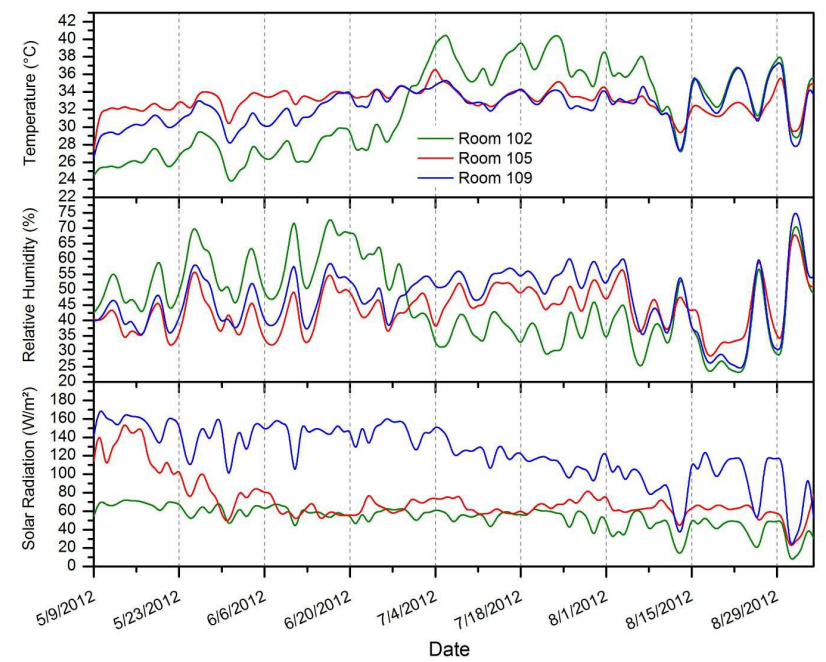

Figure 3. Daily time series of average air temperature $\left({ }^{\circ} \mathrm{C}\right)$, relative humidity (\%), and incoming solar radiation $\left(\mathrm{W} / \mathrm{m}^{2}\right)$ data collected between 5/9/12 and 9/5/12 in the Sears Plant Growth Facility located at the University of Missouri, Columbia, MO, USA.

Results showed that plants grown at increasing distance from the evaporative pads were subjected to warmer and drier conditions. Quantifying this observation in the current work substantiates the usefulness of at least one additional climate monitoring sensor positioned further from the evaporative pads to sense variable internal greenhouse microclimates. If the desire is to strike a balance between microclimate monitoring, climate control efficiency and infrastructure investment, four additional spatially distributed climate monitoring sensors is advised. For example, for the current study, one sensor to each side of the centrally located sensor approximately the same distance apart and near outside walls would improve horizontal microclimate monitoring and climate regulation. Two sensors should also be added at equal spacing above the centrally located sensor to detect vertical microclimate variation. Therefore, it is recommended that at least five internal $\mathrm{Ta} / \mathrm{RH}$ sensors be used to sufficiently detect horizontal and vertical microclimate heterogeneity within each greenhouse room. Notably, positioning of sensors should be tested and customized to balance data acquisition and climate control programming needs in any greenhouse room, and optimal positions may require changes with presence (or absence) of vegetation or other structures (i.e. tables) in the room or time of year. Ultimately, with additional sensors with proper placement, the climate controller may better actively mix the internal climate to reduce variability and promote homogenous crop growth and productivity.
Average incoming solar radiation recorded by study pyranometers in rooms 102,105 , and 109 was 52.8, 71.8, and $122.6 \mathrm{~W} / \mathrm{m}^{2}$, respectively (Table 3 ). Differences were attributed primarily to differences in the number and size of plants and the action temperatures for the automated shade screens in each room. The number and size of plants being grown affects the leaf area index (LAI, the area of leaves per unit ground surface area) in a greenhouse room [24]. Abdel-Ghany and Al-Helal (2011) [28] showed that the fraction of incoming solar radiation absorbed by plants increased with greater LAI values, which reduced the fraction of incoming solar radiation absorbed by the greenhouse floor. Room 102 contained no plants and had the shade curtains drawn for the duration of this study, which prevented average incoming solar radiation values greater than $221 \mathrm{~W} / \mathrm{m}^{2}$. The cooling system in room 105 was programmed to draw the shade curtains at $32.2^{\circ} \mathrm{C}$, which occurred regularly in July and August and prevented incoming solar radiation values larger than $425 \mathrm{~W} / \mathrm{m}^{2}$. Room 109 was programmed to draw the shade curtain at $43.3^{\circ} \mathrm{C}$, which didn't occur for the duration of the study and resulted in incoming solar radiation values frequently exceeding $500 \mathrm{~W} / \mathrm{m}^{2}$. Möller (2002) [29], Monteith and Unsworth (1990) [30], and Campbell and Norman (1998) [24] showed that light saturation for sweet pepper and barley crops occurs near $500 \mathrm{~W} / \mathrm{m}^{2}$. Therefore, the light levels in room 109 could have added detrimental levels of heat, which is not beneficial for plant growth and should be prevented through the use of shade curtains.

\subsection{Climate within Rooms}

Figure 4 shows box and whisker plots of air temperature and vapor pressure deficit using hourly data collected by centrally located greenhouse and iButton sensors while the climate control system was $\mathrm{ON}$ in each room (Table 4). Average temperatures sensed by centrally located iButton sensors were $3.22^{\circ} \mathrm{C}(9.3 \%)$ and $1.94^{\circ} \mathrm{C}(7.1 \%)$ warmer than centrally located greenhouse sensors for rooms 105 and 109 respectively. Hubbart (2011) [18] compared aspirated shielded iButton sensors with shielded iButton sensors and showed that on average $(n=61)$ non-aspirated sensors sensed temperatures $2.84^{\circ} \mathrm{C}(13.5 \%)$ warmer than the aspirated sensor (a statistically significant difference, $\mathrm{P}<0.05)$. IButton sensors may have had a warm bias based on their lack of aspiration, but differences between centrally located greenhouse and iButton sensors frequently exceeded the differences between sensors found by Hubbart (2011) [18]. This bias could explain the warmer average temperatures recorded by centrally located iButtons, but differences were especially apparent between absolute minimum and maximum values recorded by each sensor. Absolute minimum temperatures recorded by centrally located iButtons were $0.71^{\circ} \mathrm{C}(3.9 \%), 0.21^{\circ} \mathrm{C}(1.0 \%)$, and $0.20^{\circ} \mathrm{C}(1.0 \%)$ warmer than the centrally located greenhouse sensors in rooms 102, 105, and 109 respectively. However, absolute maximum temperatures recorded by centrally located iButtons were $9.28^{\circ} \mathrm{C}(29.8 \%), 4.88^{\circ} \mathrm{C}$ $(12.0 \%)$, and $6.47^{\circ} \mathrm{C}(19.0 \%)$ warmer than centrally located greenhouse sensors in rooms 102, 105, and 109 respectively. 
Average estimated vapor pressure deficit values sensed by centrally located iButton sensors were $0.57 \mathrm{kPa}(27.9 \%)$ and $0.20 \mathrm{kPa}(20.5 \%)$ greater than centrally located greenhouse sensors for rooms 105 and 109 respectively. These were statistically significant $(\mathrm{P}<0.001, \mathrm{CI}=0.05)$ differences. Differences may be attributable to the much earlier climate control shut off date in room 102 (June $29^{\text {th }}$ ) relative to the other two rooms in addition to substantially lower action temperatures for active cooling in room 102, which simultaneously reduced temperature and increased relative humidity. Reducing the action temperatures for evaporative cooling systems may lead to improved crop growth conditions, especially during extremely hot external conditions.

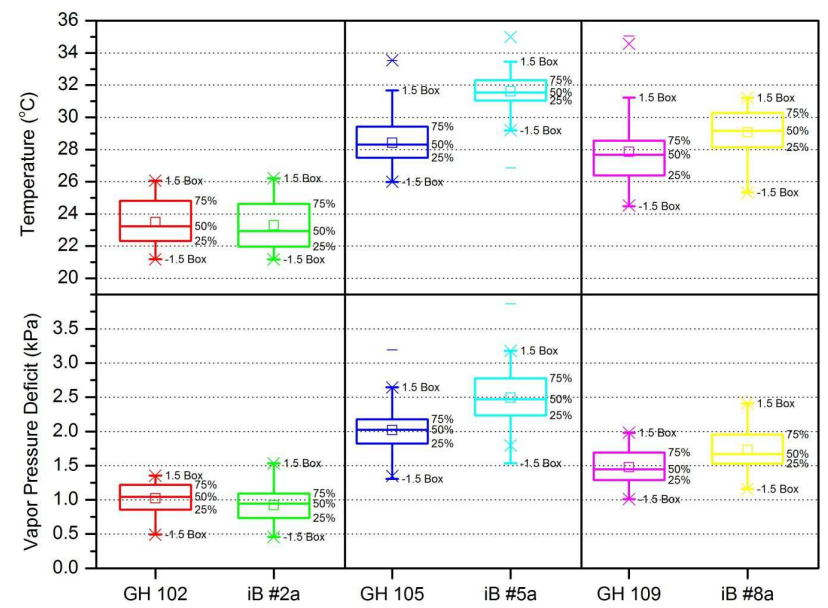

Figure 4. Box and whisker plots of hourly air temperature $\left({ }^{\circ} \mathrm{C}\right)$ and vapor pressure deficit $(\mathrm{kPa})$ data collected while the climate control system was $\mathrm{ON}$ in each room by centrally located iButton and greenhouse sensors in the Sears Plant Growth Facility located at the University of Missouri, Columbia, MO, USA. Rooms separated by vertical line. $G H=$ Greenhouse sensor, $i B=$ iButton temperature/relative humidity sensor.

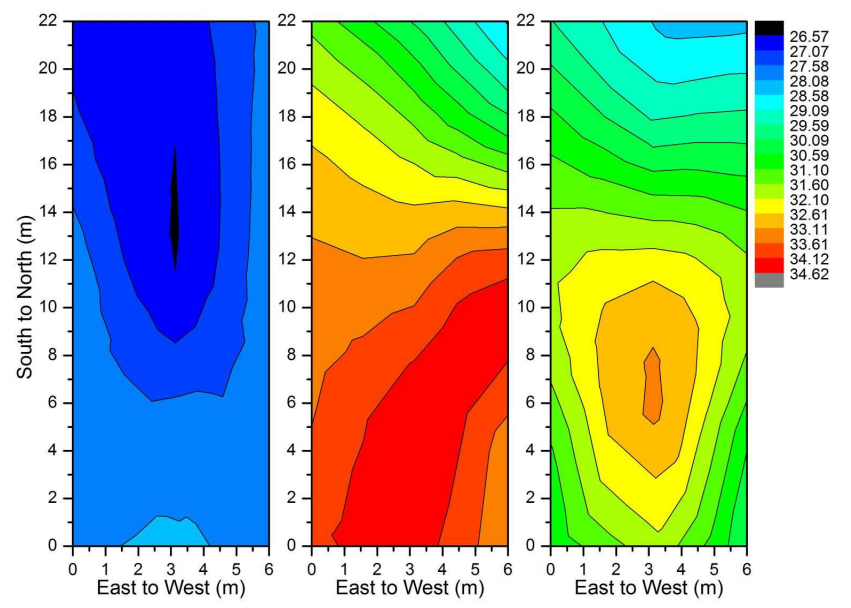

Figure 5. Spatial distribution (i.e. looking down) maps of average temperature $\left({ }^{\circ} \mathrm{C}\right)$ data while the climate control system was "ON" in (from left to right) rooms 102, 105, and 109 at the Sears Plant Growth Facility located at the University of Missouri, Columbia, MO, US

Clear north to south temperature gradients $(22 \mathrm{~m}$ room length) were shown in each room, but the least variable conditions were found in room 102 (Fig. 5). The temperature distribution in rooms 105 and 109 showed that the greatest temperature gradient occurred in the northern half of each room closest to the evaporative pads (Table 5). On average the central cross section was warmer than the south cross section, which was furthest from the cooling pads, thus indicating a reversal of the general north to south temperature gradient. Horizontal temperature gradients were affected by turbulence, which was maximized in the middle of each room farthest from the source (cooling pads), sink (exhaust fans), and further increased by obstructions to flow such as plants and benches.

The non-uniform plant distribution in each of the rooms may have also increased the temperature gradients across the northern half of each room due to cooling through evapotranspiration and restricting air flow. Lopez et al. (2010) [31] showed that bench height temperatures were about $4^{\circ} \mathrm{C}$ warmer in an empty greenhouse room relative to a greenhouse room with a mature tomato crop thereby highlighting the cooling potential of a mature crop canopy and potential warming in non-vegetated portions of the greenhouse. On this basis, greenhouse crops should be planted across as much bench space as possible to homogenize air flow through each room and increase evapotranspiration, thereby minimizing microclimate heterogeneity.

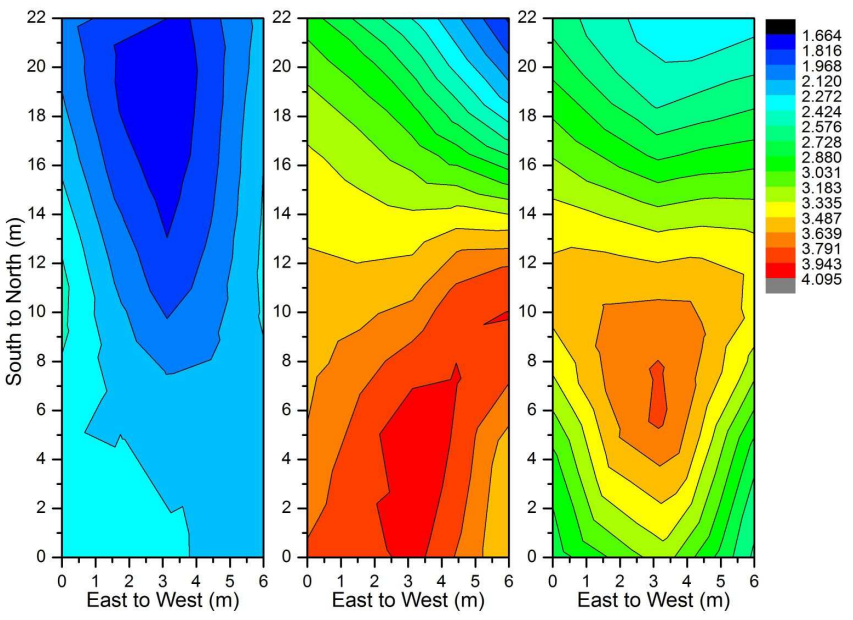

Figure 6. Spatial distribution (i.e. looking down) of average vapor pressure deficit $(\mathrm{kPa}$ ) while the climate control system was "ON" in (from left to right) rooms 102, 105, and 109 at the Sears Plant Growth Facility located at the University of Missouri, Columbia, MO, USA.

The maximum VPD values recorded by Lui et al. (2006) [21] and Guichard et al. (2005) [20] were between 2.5 and 3.0 $\mathrm{kPa}$, thus implying that plants in the greenhouse rooms of the current study were likely subjected to detrimentally high VPD values (Fig. 6). However, the investigations of Lui et al. 2006 and Guichard et al. 2005 were performed in greenhouses with uniform plant densities of 7.5 rose plants $/ \mathrm{m}^{2}$ and 2.1 tomato plants $/ \mathrm{m}^{2}$ respectively. Therefore, evapotranspiration associated with a homogenous crop distribution is important to consider in terms of minimizing greenhouse microclimate heterogeneity. Al-Helal and Abdel-Ghany (2011) showed that on a sunny day $34.4 \%$ of the net radiation present above the canopy was converted into latent heat by evapotranspiration in 
a greenhouse where the crop's leaf area index (LAI) was 3. Clearly, evapotranspiration is an important process when considering greenhouse climate control and greater LAI will reduce microclimate heterogeneity and simultaneously reduce diurnal greenhouse microclimate variability.

Daily averages of bench height (1m) temperature data showed how the climate control system stabilized the internal climate while it was operating in each room (Fig. 7). However, air temperatures at $3 \mathrm{~m}$ were consistently above the $32^{\circ} \mathrm{C}$ threshold established by Baudoin et al. (1990) [27] for stomata closure, except for room 102 while the climate control system was ON. Plants during this study had heights of approximately $2 \mathrm{~m}$. Corn plants were in pots on the floor and soybean plants were in pots on $1 \mathrm{~m}$ benches. Results of the current study indicate that with increasing height, plants were subjected to increasingly unfavorable climate conditions characterized by an average lapse rate for all rooms of $2.9^{\circ} \mathrm{C} / \mathrm{m}$ while the climate control system was ON. Room 109 consistently showed the strongest vertical temperature gradients (Fig. 7), possibly a results of the desire to maximize light levels. As a result however, the active cooling system was run more frequently to maintain the desired average optimal temperature of $22.5^{\circ} \mathrm{C}$. The evaporative pads and exhaust fans were located at approximately bench height $(1 \mathrm{~m})$ resulting in enhanced airflow at that height. Temperature at $3 \mathrm{~m}$ was strongly dependent on the magnitude of turbulent mixing, which could be artificially increased by using horizontal circulation fans.

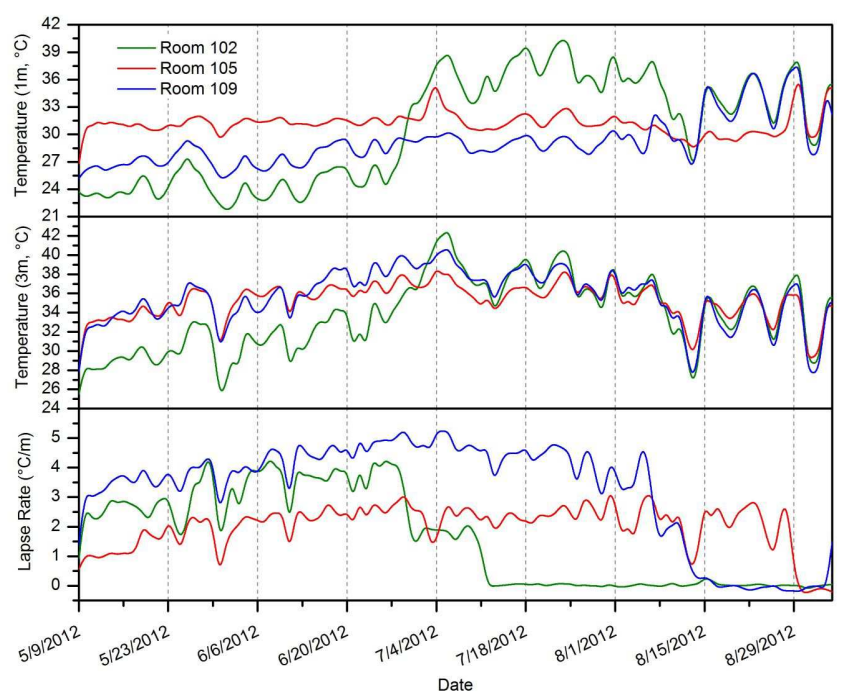

Figure 7. Daily time series of air temperature $\left({ }^{\circ} \mathrm{C}\right)$ at bench height $(1 \mathrm{~m})$ and $3 m$, lapse rate calculations $\left({ }^{\circ} \mathrm{C} / \mathrm{m}^{-1}\right)$ collected between $5 / 9 / 12$ and 9/5/12 using iButton sensors deployed at the Sears Plant Growth Facility located at the University of Missouri, Columbia, MO, USA.

On average, spatially distributed iButton sensors detected significantly $(\mathrm{P}<0.05, \mathrm{CI}=0.05)$ warmer and drier conditions than centrally located greenhouse sensors. Results indicate that observed warmer and drier conditions could in-part be attributed to differences in greenhouse sensors versus sensors used in the current work. However, a goal of this study was to show whether a single centrally located climate monitoring sensor sufficiently represented the overall internal greenhouse microclimate. Results indicate that substantial microclimate heterogeneity exists with mean horizontal temperature gradients of as much as $5.0^{\circ} \mathrm{C} / \mathrm{m}$ (Fig. 5), and mean horizontal VPD gradients of $1.5 \mathrm{kPa} / \mathrm{m}$ (Fig. 6). Most substantially, the maximum vertical temperature gradient was $11.65^{\circ} \mathrm{C} / \mathrm{m}$. Microclimate heterogeneity of this magnitude undoubtedly creates challenging and often uneven crop growing conditions.

\section{Conclusions}

Maximum greenhouse crop growth and production is achieved in part by providing optimal crop growth conditions homogenously throughout a greenhouse. However, many contemporary greenhouses have evaporative pad cooling systems that can inherently create horizontal and vertical temperature gradients. Microclimate gradients variably influence crop growth and impact overall production, but cannot be sensed by a single centrally located climate monitoring sensor. This study included spatially distributed instruments $(\mathrm{n}=21 / \mathrm{room})$ that provided necessary information to quantitatively characterize greenhouse microclimate heterogeneity and provide recommendations for contemporary greenhouse managers who may wish to better control greenhouse climate.

Exceptional external climate conditions during this study improved the value of the current work in that climate conditions provided a worst case scenario for drought conditions and greenhouse management. Uniformly distributed sensors detected average internal greenhouse conditions $3.7^{\circ} \mathrm{C}(12.9 \%)$ warmer and $4.6 \%$ lower relative humidity values than the centrally located climate monitoring greenhouse sensors between May $9^{\text {th }}$ and September $5^{\text {th }}, 2012$. Additionally, spatially distributed sensors detected room average temperatures that were $5.3^{\circ} \mathrm{C}(24.2 \%), 6.5^{\circ} \mathrm{C}(24.5 \%)$, $9.7^{\circ} \mathrm{C}(43.1 \%)$ warmer than average optimal day and night temperatures (i.e. programmed conditions) in rooms 102, 105, and 109, respectively. Statistical analysis showed that all comparisons of room average temperature and relative humidity data collected by greenhouse and spatially distributed iButton sensors were significantly different $(\mathrm{P}<$ $0.028, \mathrm{CI}=0.05)$. The climate variability identified in the current work showed that the driving gradient for vapor flux (VPD) varied substantially based on plant height and location within the greenhouse. One way to counteract this problem may be to maximize plant density and leaf area index within each greenhouse room to increase the magnitude of spatially distributed evapotranspirational cooling.

The maximum room averaged vertical temperature gradient was $11.65^{\circ} \mathrm{C} / \mathrm{m}$, indicating that with increasing plant height, plants grew into increasingly harsh microclimate conditions. Strong vertical temperature gradients such as these could be ameliorated through the use of ceiling mounted circulation fans. Greenhouse managers may wish to draft two separate sets of action temperatures based on the primary climate control objective (heating or cooling). Furthermore, if particularly hot and sunny conditions are 
forecast further adjustments to action temperatures should be made such as reducing the activation temperature or intervals between stages of the cooling system. Regular cleaning or replacement of evaporative pads and proper calibration of climate monitoring sensors are also simple ways to reduce greenhouse climate control system error. Installing an internally mounted incoming solar radiation sensor may also reduce the climate controller's error relative to an externally mounted incoming solar radiation sensor. It is recommended that multiple properly located and installed internal $\mathrm{Ta} / \mathrm{RH}$ sensors be used to sufficiently detect horizontal and vertical microclimate heterogeneity within each greenhouse room. Additional climate monitoring sensors would allow the climate control system to identify and respond to heterogeneous internal climates, thereby improving internal greenhouse climate homogeneity and accompanying plant productivity.

\section{Acknowledgements}

Gratitude is extended to the Sears Plant Growth Facility Committee, particularly Michelle Brooks and Rich Wilman. Special thanks are extended to scientists of the Interdisciplinary Hydrology Laboratory, the CAFNR Center for Watershed Management and Water Quality, the School of Natural Resources Water Resources Program, and multiple reviewers whose comments improved the quality of the article.

\section{References}

[1] Gruda, N. 2005. Impact of Environmental Factors on Product Quality of Greenhouse Vegetables for Fresh Consumption. Critical Reviews in Plant Sciences 24.3: 227-247.

[2] Pawlowski, A., J.L. Guzman, F. Rodríguez, M. Berenguel, J. Sánchez, and S. Dormido. 2009. Simulation of Greenhouse Climate Monitoring and Control with Wireless Sensor Network and Event-Based Control. Sensors 9.1: 232-252.

[3] Bot, G.P.A. 2003. The Solar Greenhouse; Technology for Low Energy Consumption. Acta Horticulturae (ISHS) 611: 61-71.

[4] Sethi, V.P., and S.K. Sharma. 2007. Survey of Cooling Technologies for Worldwide Agricultural Greenhouse Applications. Solar Energy 81.12: 1447-1459.

[5] Kittas C., N. Katsoulas, and T. Bartzanas. 2012. Greenhouse Climate Control in Mediterranean Greenhouses. Journal of Agrifood Studies (CEA) 3: 89-114.

[6] Kittas C., T. Bartzanas, A. Jaffrin. 2003. Temperature Gradients in a Partially Shaded Large Greenhouse Equipped with Evaporative Cooling Pads. Biosystems Engineering 85.1: 87-94.

[7] Lopez, A., D. Valera, F. Molina-Aiz, and A. Pena. 2012. Sonic Anemometry to Evaluate Airflow Characteristics and Temperature Distribution in Empty Mediterranean Greenhouses Equipped with Pad-fan and Fog Systems. Biosystems Engineering 113: 334-350.

[8] Kramer P.J., Boyer J.S. 1995. Transpiration and the Ascent of
Sap. Water Relations of Plants and Soils. San Diego: Academic, 209.

[9] Van Pee, M. and D. Berckmans, 1999. Quality of Modeling Plant Responses for Environment Control Purposes. Computers and Electronics in Agricuture. 22.2-3: 209-216.

[10] Boulard, T. 2012. Recent Trends in Greenhouse Microclimate Studies and Contribution of CFDs. Acta Horticulturae (ISHS) 952: 739-748.

[11] Grange, R.L., D.W. Hand. 1987. A Review of the Effects of Atmospheric Humidity on the Growth of Horticultural Crops. Journal of Horticultural Science 62: 125-134.

[12] Baille, M., A. Baille, and D. Delmon. 1994. Microclimate and Transpiration of Greenhouse Rose Crops. Agricultural and Forest meteorology 71: 83-97.

[13] Gholipoor M., S. Choudhary, T.R. Sinclair, C.D. Messina, M. Cooper, 2012. Transpiration Response of Maize Hybrids to Atmospheric Vapour Pressure Deficit. Journal of Agronomy and Crop Science 199.3: 155-160.

[14] Gholipoor M., P.V.V. Prasad, R.N. Mutava, and T.R. Sinclair, 2010. Genetic variability of transpiration response to vapor pressure deficit among sorghum genotypes. Field Crops Research 119: 85-90.

[15] Bunce, J.A. 2003. Effects of Water Vapor Pressure Difference on Leaf Gas Exchange in Potato and Sorghum at Ambient and Elevated Carbon Dioxide Under Field Conditions Field Crops Research 82.1: 37-47.

[16] Fletcher A.L., T.R. Sinclair, and L.H. Allen. Jr, 2007. Transpiration Responses to Vapor Pressure Deficit in Well Watered 'Slow Wilting' and Commercial Soybean. Environmental and Experimental Botany 61: 145-151.

[17] Hubbart, J., T. Link, C. Campbell, and D. Cobos. 2005. Evaluation of a Low-cost Temperature Measurement System for Environmental Applications. Hydrological Processes 19.7: 1517-1523.

[18] Hubbart, J.A. 2011. An Inexpensive Alternative Solar Radiation Shield for Ambient Temperature and Relative Humidity Micro-sensors. Journal of Natural and Environmental Sciences 2.2: 9-14.

[19] Blandford T.R., K.S. Humes, B.J. Harshburger, B.C. Moore, V.P. Walden. 2008. Seasonal and Synoptic Variations in Near-Surface Air Temperature Lapse Rates in a Mountainous Basin. Journal of Applied Meteorology and Climatology 47: 249-261.

[20] Guichard, S., C. Gary, C. Leonardi, N. Bertin. 2005. Analysis of Growth and Water Relations of Tomato Fruits in Relation to Air Vapor Pressure Deficit and Plant Fruit Load. Journal of Plant Growth Regulation 24: 201-213.

[21] Liu, F., Y. Cohen, M. Fuchs, Z. Plaut, and A. Grava. 2006. The effect of vapor pressure deficit on leaf area and water transport in flower stems of soil-less culture rose. Agricultural Water Management 81:216-224.

[22] Zar, J.H. 1999. Biostatistical analysis. $4^{\text {th }}$ ed. Upper Saddle River, NJ: Prentice Hall.

[23] Buck, A.L. 1981. New Equations for Computing Vapor Pressure and Enhancement Factor. Journal of Applied Meteorology 20.12: 1527-1532. 
[24] Campbell, G.S., and Norman, J.M. 1998. Water Vapor and Other Gases. Introduction to Environmental Biophysics. New York: Springer. 37-50.

[25] Akima,H. 1978. A method of bivariate interpolation and smooth surface fitting for irregularly distributed data point. ACM Transactions on Mathematical Software, 4(2): 148-159.

[26] Svoboda, M., D. LeComte, M. Hayes, R. Heim. 2002. The Drought Monitor. Bulletin of the American Meteorological Society 83.8: 1181-1190.

[27] Baudoin, W.O., I.C. Denis, M. Grafiadellis, R. Jimenez, G. La Malfa, P.F. Martinez-Garcia. 1990. Protected cultivation in the Mediterranean climate. Food and Agriculture Organization of the United Nations, paper 90.

[28] Abdel-Ghany, A.M., I.M. Al-Helal. 2011. Energy Partition and
Conversion of Solar and Thermal Radiation into Sensible and Latent Heat in a Greenhouse under Arid Conditions. Energy and Buildings 43: 1740-1747.

[29] Möller, M. 2002. The Effect of Insect-proof Nets on Exchange of Mass and Momentum in a Screenhouse for pepper Cultivation in Central Israel. Diploma Thesis, Department of Meteorology, TU Dresden.

[30] Monteith, J., and M. Unsworth. 1990. Principles of Environmental Biophysics, $2^{\text {nd }}$ edition. Butterworth-Heinemann, Oxford, 255.

[31] Lopez, A., D. Valera, F. Molina-Aiz, and A Pena. 2010. Experimental Evaluation by Sonic Anemometry of Airflow in a Mediterranean Greenhouse Equipped with a pad-fan Cooling System. Transactions of the ASABE, 53(3), 945-957. 